\title{
Modelling the Drivers of the UK Multi-let Industrial Property Market: An Exploratory Study
}

\author{
David M Higgins \\ Professor of Real Estate, School of the Built Environment, Birmingham City University, \\ Birmingham. \\ Email:david.higgins@bcu.ac.uk \\ Tsvetomira (Tess) Vincent \\ General Practice Surveyor, Place Partnership, Worcester. \\ Email: tsvetomira.vincent@gmail.com \\ Peter Wood \\ Senior Real Estate Lecturer, School of the Built Environment, Birmingham City University, \\ Birmingham. \\ Email:peter.wood@bcu.ac.uk
}

\begin{abstract}
Multi-let industrial (MLI) estates are an emerging $£ 15$ billion UK real estate asset class that can offer attractive returns, a diversified income base, constrained supply and extensive management opportunities to add value within an operational platform. This investment appeal is supported by the evolving MLI occupier market with the growth of small to medium enterprises (SME) requiring modern urban business space driven in part by technology advances offering new streams of supply chain connectivity between businesses and potential clients at a local level. In detailing these key MLI property features, current research is limited and focused primarily on market commentary. New knowledge on the MLI property market can provide a platform creating interesting opportunities for fund managers with an intensive management engagement strategy.
\end{abstract}

To understand more about MLI properties, this study utilises a hedonic pricing model to quantify property values as a function of defined variables. The dataset used for this research is a sample portfolio of 26 multi-let industrial properties. The dataset was analysed alongside eleven physical, financial and locational factors. Interestingly, the hedonic pricing model results showed that only four characteristics are value-affecting across the selected properties: namely i) Granularity of the property income, ii) Distance from the nearest motorway, iii) Distance to the nearest town centre and iv) Gross internal floor area. A chi-test confirmed that there was no significant difference between the modelled values and the supplied property valuations. This preliminary study offers valuable insight into MLI property market drivers and could easily form a simple decision-making tool to examine potential MLI opportunities in this developing real estate asset class.

Keywords: Multi-let industrial (MLI) properties; Hedonic pricing model; Key property characteristics; Small to medium enterprises (SME)

Email Contact : david.higgins@bcu.ac.uk 


\section{Modelling the Drivers of the UK Multi-let Industrial Property Market: An Exploratory Study}

\section{INTRODUCTION}

Developmental and connective forces are changing the economic, social and financial environment within which businesses operate. These structural changes in the flow of goods, capital and people are transforming the real estate landscape, to an extent where previously blue-chip investments backed by long lease covenants are looking less attractive with the breakdown of traditional marketplaces and operational platforms. These changes and the ongoing shift in workplace activities are redefining the established demands for space and creating potentially new investment grade real estate markets across urban locations.

Current theory and practice have identified the potential of the industrial property market to capitulate the positive spillover created by technology-lead emerging e-commence marketplace. In many instances, it is the transformation of the supply chain which offers new linkages both between businesses, and more importantly their customers. In identifying the industrial property market potential, there are several industrial market sectors which have unique features and operational characteristics which need to be established as investment returns can vary across the industrial classes alongside value added opportunities. See Figure 1 for industrial property market sectors as at December 2019.

\section{Figure 1. UK Industrial Property Market Categories}

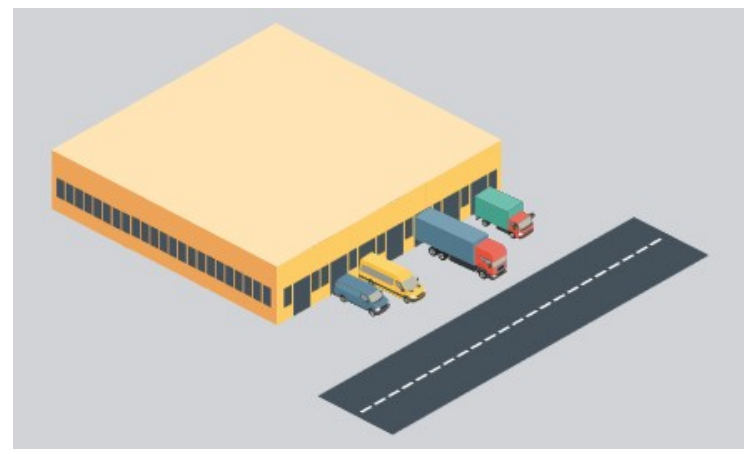

Logistics $(10,000$ to $100,000+$ sqm)

Market Yields: $4.0-5.0 \%$

Lease Terms: 9-12 years

Management: Low

Generally large purpose built, self-

contained warehouses, let to an

established tenant, normally used for

storage located on key transport nodes.

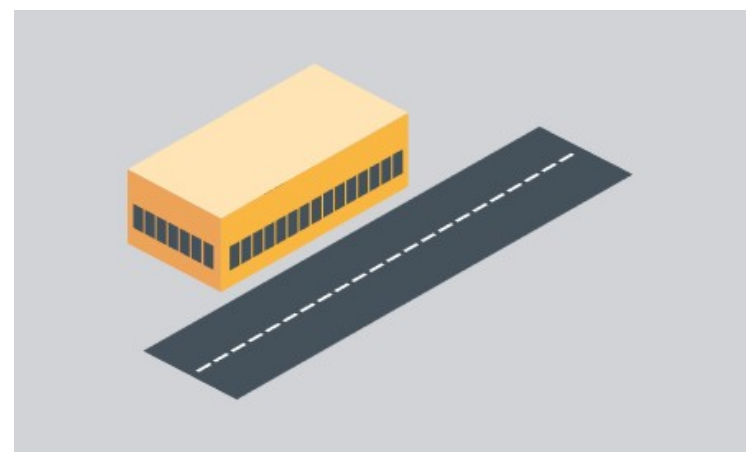

Solus Warehouse (1,000 to $10,000 \mathrm{sqm})$

Market Yields: $4.5-5.5 \%$

Lease Terms: $9-12$ years

Management: Low

Stand-alone self-contained warehouses, let to a single tenant, located in industrial areas near or on major road networks. 

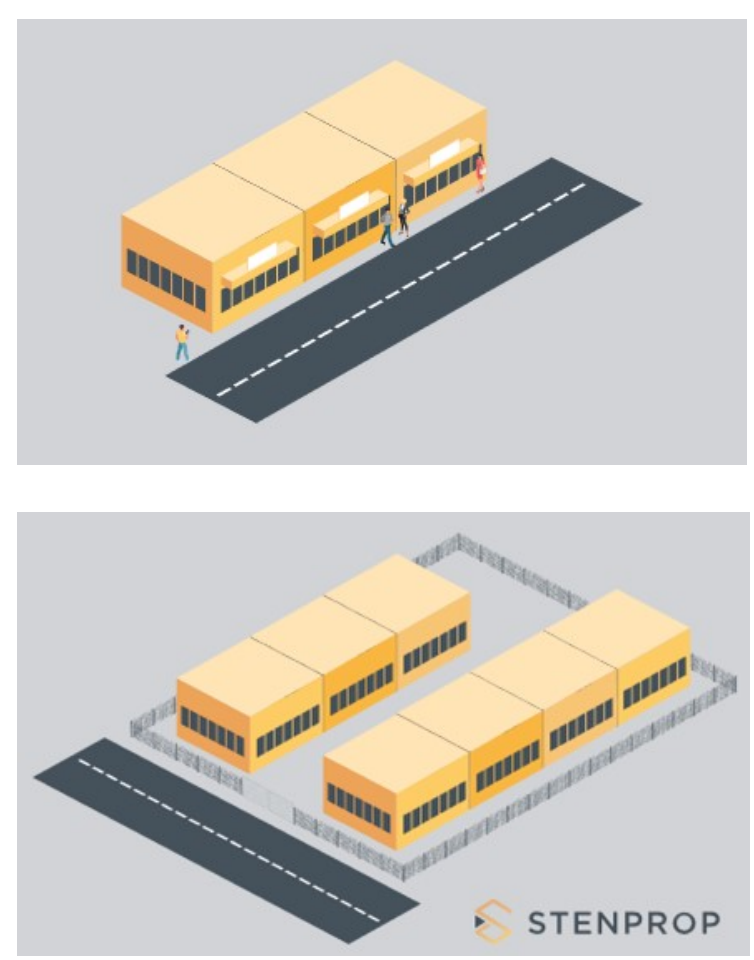

Trade Counter (100 to 2,000 sqm)

Market Yields: $5.0-6.0 \%$

Lease Terms: 5-10 years

Management: Medium

Highly prominent units with retailstyle frontages. Located on a main road within or on the edge conurbations.

\author{
Multi Let Industrial (50 to $1,000 \mathrm{sqm}$ ) \\ Market Yields: $6.0-8.0 \%$ \\ Lease Terms: 3-5 years \\ Management: High \\ A cluster of 5-50 units arranged in terraces let \\ to multiple tenants. Units comprise a large \\ open space accessed through a roller shutter \\ door with approx. $10 \%$ office content.
}

Adapted: Stenprop 2019a, Authors

Figure 1 details the industrial property range, each with unique features covering both physical, financial and legal characteristics. Operationally, with relatively long leases and standalone aspects, Logistics, Solus and Trade Centres have relatively low ongoing management requirements compared to MLI properties which often comprise multi-purpose, flexible space, arranged in terraces and let to multiple local SME tenants in a competitive market environment. In this instance, similar to aspects of the retail sector, intensive management can offer the opportunity to engage with the entire building population to create a vibrant interconnected community and so improve potential investment returns alongside offering value added facility oriented services.

In recognising the communal and economic advantages of MLI properties, official data and market reports on MLI properties are limited with one major UK exception, see Gerald Eve (2018) report. Knowing what characteristics of MLI estates influence their values can improve the investment decision-making and subsequently provide better insight into this emerging asset class. This can be achieved by examining and modelling MLI performance and determinant characteristics.

For this study, secondary data was sourced from a leading UK real estate organisation. The information provided covers a sample of 26 UK multi-let industrial properties. In addition, third party information was sourced from government departments and GPS mapping providers. Twenty Seven property characteristics were considered initially for the quantitative model with eleven selected. This information provided the input data to perform the hedonic price modelling which is based on a regression equation that can use panel or dummy variables assigned to individual or group of characteristics. See Malpezzi (2003) for a detailed explanation on single equation hedonic pricing models.

Following this introduction, Section Two provides a literature review covering the impact of innovation, growth of SME and the MLI property market. Section Three details the selected methodology and associated data. Section Four provides the empirical findings and property investment implications and the last section gives concluding comments. 


\section{LITERATURE REVIEW}

In this chapter, the review of literature covers three key areas, innovation in the local business context, the growth of small to medium enterprises (SME) and the multi-let industrial (MLI) property market.

\section{Innovation and Local Business Opportunities}

The scale of change across society driven by new technology is immense and has created new business opportunities and risks. In many aspects, the rapid advances of the digital interface have offered a new medium for capturing, commutating and exchanging data. This has led to the necessary reinvention of many organisations as well-known products and traditional marketplaces gradually disappear. In addition, driven by new technology, the nature of work in many service-oriented industries are transferring from full time to contract focused employment alongside evidence of increased entrepreneurship, especially in the Generation Y (Millennials) and Generation Z age group (Cushman and Wakefield 2017, Goldin and Kutarna 2017).

In defining the emerging workplace, businesses are breaking apart the entire value chain, where connectivity is offering new modes of operation and methods of trading. New linkages created by recent technological upgrades, for example: Cloud computing, artificial intelligence and wireless technology, have led to the emergence of new industries, particularly the e-commerce sector with associated operational support facilities. In many instances this is where the physical world is supporting the new digital footprint (Brynjolfsson and McAfee 2014).

In understanding how technology is transforming economies, another major force is globalisation. Spence (2011) explains in detail how the integration of global markets is leading to major dislocations, especially in labour markets. In recognising this, lower costs provided by innovation can benefit local enterprises with flexibly and efficiently in offering individual products to customers, for example: 3D printing process. In many instances innovation accelerates the diffusion of knowledge and is enabling the emergence of new startup business models, which can enable organisations to scale very quickly, often with few employees, tangible assets or geographic footprint (OECD 2018).

\section{Growth of Small to Medium Enterprises}

Innovation and deregulation are creating an environment for enterprisers and small business to succeed. This is recognised and supported by governments as evident by the recent growth of small and medium enterprise (SME) in the UK, which is classified in broad terms as any business with fewer than 250 employees. In 2018, there were 5.7 million SMEs in the UK, up from 5.5 million the previous year. This figure has increased every year since the year 2000 and now represents over $99 \%$ of all businesses in the UK (Rhodes 2018).

For a comparison, the European Commission collects slightly different SME data across Europe, it covers 'non-financial business economy' and excludes low income SME's. Whilst it is inconsistent with the UK government data, it provides a good portrait of the large contribution SME's make to the UK economy within key categories of employment and the impact on the economy, see Table 1. 
Table $1 \quad$ UK Profile: Small to Medium Enterprises

\begin{tabular}{|c|c|c|c|c|c|c|}
\hline \multirow{2}{*}{ Categories } & \multicolumn{2}{|c|}{ Number of Enterprises } & \multicolumn{2}{|c|}{ Number of Person Employed } & \multicolumn{2}{|c|}{ Value Added } \\
\hline & Number & Share & Number & Share & Billion Euro & Share \\
\hline SMEs & $2,137,005$ & $99.7 \%$ & $10,796,382$ & $54.0 \%$ & 656 & $51.2 \%$ \\
\hline Large & 6,546 & $0.3 \%$ & $9,200,319$ & $46.0 \%$ & 628 & $48.8 \%$ \\
\hline Total & $2,143,551$ & $100.0 \%$ & $19,996,701$ & $100.0 \%$ & 1,284 & $100.0 \%$ \\
\hline
\end{tabular}

Source: European Commission 2017

Table 1 shows the UK SME market generates slightly more than half of total employment and value added (contribution to UK economy) when compared to organisations with more than 250 employees. Interestingly, this is slightly lower than the EU averages of $66.4 \%$ and $56.8 \%$ respectively and so demonstrates in part that there are continuing prospects for the SME market to grow as a proportion of the UK economy (European Commission 2017).

In recognising SMEs are the backbone of the economy, many SME require assistance to boost productivity and support to expand business and increase impact. The role of national and local government is crucial in encouraging SMEs. The UK government's industrial strategy, which was launched in November 2017, aims to address this challenge as part of a broad strategy to transform the UK economy by investing in five key areas covering: ideas, people, infrastructure, business environment, and places. To assist in this area, the UK government has created a network of local Growth Hubs, which deliver local business support. They offer a single local access point for business support, effectively a 'front end' for government programmes and other economic support (European Commission 2017, LEP Network 2019).

\section{Multi-Let Industrial Property Market}

For institutional investors, industrial real estate recently captured the limelight with their comparatively high yields and potential value appreciation driven in part by the structural changes in the economy with the growth of new technology. Most notably, those real estate assets exposed to logistics and distribution-related tenants and those providing multi-tenanted, diversified income streams. In recent years, industrial properties have regularly outperformed alterative UK real estate asset classes as their yields compress to match and in locations fall below that of offices (MSCI 2018).

While retail-related warehousing and distribution has long been a significant component of industrial property demand for institutions, MLI real estate has emerged as offering an income diversification across the tenant base with different sized units let to multiple occupiers. The urban locations can support distribution networks to service e-commerce and so offering multi-channel retailing and last mile delivery facilities. This is an unparalleled market development as shown by the MSCI standard industrial property class (proxy for MLI property sector) returning over $20 \%$ total returns in 2017 compared to single digit performance of alternative core real estate markets (Gerald Eve 2018, MSCI 2018, Schroder 2014).

The MLI property market is estimated to be in the region of 10 million sqm and $£ 15 \mathrm{bn}$ in value which represents less than $2 \%$ of the current UK commercial investment property market. The investment market is changing as property companies appear to be the main divestors of MLI assets, being replaced by overseas investors and UK institutions. Portfolio deals have featured highly, typically accounting for around $40 \%$ of the total volume each year, giving investors rapid large scale exposure into the growing MLI property investment marketplace (Gerald Eve 2018, IPF 2018, Property Industry Alliance 2017, MSCI 2018).

Gerald Eve (2018) reported on approximately 6.5 million sqm of the UK MLI property market. Recorded space occupancy showed a move away from the traditional 
trade/manufacturing operations to more advanced business focused activities, as shown in Figure 2.

\section{Figure 2 Multi-Let Industrial Occupiers by Industry Sectors}

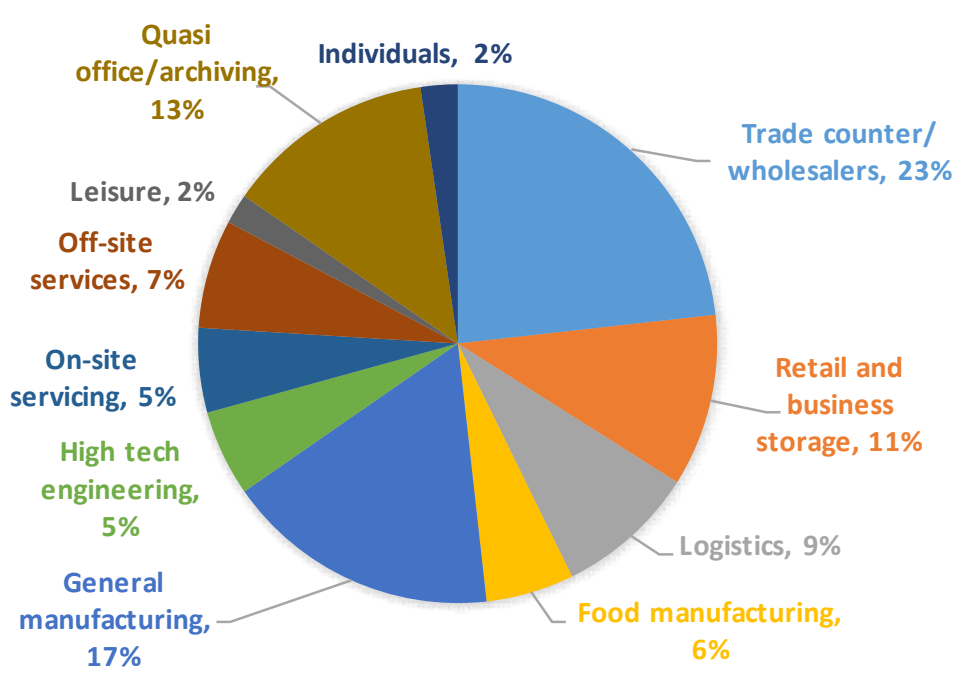

Source: Gerald Eve 2018

Figure 2 highlights retailing and logistics as the largest proportion of MLI occupied floorspace by business activity. This includes trade counters, retail and business storage and dedicated logistics which accounts for $43 \%$ of occupied space. This is followed by manufacturing accounting for $27 \%$ with smaller segments represented by quasioffices/archiving 13\% and onsite servicing (ie MOT centres) and off-site servicing (ie plumbers, electricians) collectively on a similar proportion. Interestingly, there are UK geographical disparities with logistics floorspace higher in London and the South East compared to regional locations (Gerald Eve 2018).

Furthermore, to improve income returns, Gerald Eve (2018) highlighted the importance of occupier mix to a MLI estate. They discussed two areas i) one business type is likely to congregate where the business conditions of the estate are generally advantageous for the business operations, ie good motorway access or road frontage, and ii) occupier clustering can drive collective value, for example: estate establishes itself as a destination with a range of building trade counter occupiers that provides a one-stop location for tradespeople and the local DIY community.

In recognising the recent interest in MLI estates, Stenprop (2019a) explained that often the value is in the location rather than the lease with MLI estates generally situated in and around densely populated conurbations where land values may restrict new MLI supply when compared to alternative development opportunities. This is made worse as the UK MLI property market is fragmented with no dominant stakeholders, as in the occupier context, a typical SME tenant is a small owner-managed businesses. Likewise, the MLI property investment market has a diverse ownership profile, with no dominant property investors unlike the logistic warehouse sector which have competing global and national property funds that both develop and own industrial and logistics property. In developing the MLI property investment market there are opportunities to enhance investor income through efficiencies of scale, technology platform upgrades, and innovative management techniques. This creates the ability to offer a greater range of add-on services and products to the occupier/customer base (Stenprop 2019b). 
In summary, the literature review highlighted the impact of new technology on the industrial market alongside the growth of the SME sector. The current buoyant MLI property market has the potential to generate ongoing improved returns with active asset management on improved knowledge of characteristics which influence MLI real estate values.

\section{METHODOLOGY}

Derived from Lancaster's (1966) consumer demand theory, the Hedonic Price Model (HPM) is based on the idea that property prices can differ with respect to various characteristics across property type, physical characteristics and proximity to specific locations etc. To reveal the empirical relationship between the property price and these characteristics, regression analysis is adopted as the primary research tool. In recognising HPM has restrictions, see McMillan and Redfern (2010) and Wei and Qi (2012), the study of real estate commodities by Ahlfeldt (2011) concluded that the HPM model can performs satisfactorily. See Malpezzi (2003) and Bourassa et al (1999) for more information on hedonic property pricing models.

Following the classification of hedonic modelling determinants within housing characteristic literature, see: Sirmans et al (2005) and Xiao (2017), this research selected a range of available locational, financial and physical attributes to model the value of the MLI real estate assets. This can be demonstrated in the following equation:

\section{Equation 1}

$$
\mathrm{y}_{\mathrm{i}}=\int(\mathrm{P}, \mathrm{F}, \mathrm{L})
$$

Where: MLI property value $(y)$ is a function of $P$, which presents the physical property features; $F$, financial performance; and $L$, locational factors.

In defining the determinant categories, as part of the information collecting process, datasets can be initially constructed based on the 26 MLI properties for the selected independent variables. A range of datasets can be calculated from multiple sources, which are linked directly to the dependent variable, for example: rents, and indirectly, for example: weighted average lease expiry. See Table 2.

\section{Table 2 Initial MLI Property Determinants}

\begin{tabular}{|l|l|}
\hline $\begin{array}{l}\text { Determinant } \\
\text { Categories }\end{array}$ & MLI Property Datasets \\
\hline Physical & $\begin{array}{l}\text { Gross Internal Floor Area, Average Unit Size, Number of Tenants, Occupancy Rate, } \\
\text { Total Number of Units, Gross External Area, Land Area, Parking Bays, Building } \\
\text { Age, Floor to Ceiling Height, Office to Industrial Space Ratio. }\end{array}$ \\
\hline Financial & $\begin{array}{l}\text { Purchase Price, Bank Valuation, Property Performance per Annum, £/sqm at time of } \\
\text { purchase, Current Market Rent, Current Passing Rent, Property Income Granularity, } \\
\text { Weighted Average Lease Expiry. }\end{array}$ \\
\hline Locational & $\begin{array}{l}\text { Percentage of Deprivation, Distance to Main Road Motorway/A Road, Distance to } \\
\text { Major Town, Access to Public Transport, Supply of Labour, Vicinity to Passing } \\
\text { Car/Foot Traffic, Telecommunication Facilities. }\end{array}$ \\
\hline
\end{tabular}

Table 2 shows a range of possible MLI measureable property related characteristics. For cross sectional statistical modelling there are the following issues:

i. Securing complete data across the whole property portfolio can be challenging as often individual properties have incomplete third party information. 
ii. Often datasets are based on the same primary sourced information and in instances many figures are comparable, for example: number of tenancies and occupancy rates. These relationships provide high correlation readings and so several datasets can be tested for their statistical relationship and discarded.

iii. Key datasets can be considered as a property value catalyst and would dominant any statistical modelling which mirror traditional valuation inputs, for example: Current Market Rents.

This research selected eleven determinants that are deemed to have an independent impact on MLI property values. Their directional impact on the dependent variable needs to be considered as this can be reviewed and proven at a later stage with reference to the hedonic price model outputs. See Table 3.

\section{Table $3 \quad$ Impact of Selected Determinants on Property Prices}

\begin{tabular}{|l|c|}
\hline \multicolumn{1}{|c|}{ Determinant } & Impact on Price \\
\hline Number of Tenants in the Property & $+/-$ \\
\hline Vacancy percentage & - \\
\hline Number of Units in the Property & $+/-$ \\
\hline Granularity of the Property Income & $+/-$ \\
\hline Percentage of Deprivation in the Local Area of the Property (2014) & $+/-$ \\
\hline Distance to Motorway & - \\
\hline Distance to Major A-road & - \\
\hline Distance to Major Town (Central Post Office) & - \\
\hline Gross Internal Floor Area & + \\
\hline Weighted Average Lease Expiry per annum & + \\
\hline Asset Performance per annum & + \\
\hline
\end{tabular}

Table 3 details the selected independent variables and the suggested directional impact with reference to the dependent (property value) variable. It implies that property prices will increase by additional income, floor area and lease term. Property prices are assumed to be inversely proportional to vacancy levels, distance to Motorway/major A-road and major town centres. The impact from number of units and tenant's numbers alongside property income granularity and local area deprivation is unclear at this stage of the research.

Of interest is the Granularity of the Property Income. This is the weighted significance of the income to the selected MLI property relative to the average number of tenancies within the portfolio. See Equation 2

Equation 2 Granularity index $=\sum(\alpha \mathrm{X}) * \frac{100}{\mathrm{f}}$

Where:

$\alpha=$ the constant expressing the weighting given to each property

$\mathrm{X}=\underline{\text { frequency of tenancies in individual properties }}$

total number of tenancies in MLI portfolio

$\mathrm{f}=$ range of tenancies in the MLI portfolio

This method provides an appropriate process to identify income patterns across the MLI properties, as it measures the frequency of the occupiers in each MLI property to the total portfolio. The result acts as a diversification measure for the number of tenants in individual MLI properties. 
Likewise, local area deprivation factor offers a neighbourhood profile for the MLI estate relating to surrounding social and community circumstances. Created for Department for Communities and Local Government, the index comprises of a basket of indicators, these include income, employment, education, health, crime, housing and living environment. As across the home nations (England, Scotland etc) there appears to be different index scales, the deprivation factor was converted to a percentage reading.

\section{RESULTS}

Following on the work by Malpezzi (2003), the linear regression analysis was used to find the relationship between property values and the independent determinants. The results of the linear regression analysis are presented in Table 4.

Table 4

Linear Regression Analysis

\begin{tabular}{|l|c|c|c|c|}
\hline \multicolumn{5}{|c|}{ Regression Statistics } \\
\hline \multicolumn{1}{|c|}{ R Square 0.90 } & Coefficients & Standard Error & $t$ Stat & P-value \\
\hline Explanatory Variables & 29.46 & 20.27 & 1.45 & 0.17 \\
\hline Intercept & -0.46 & 0.79 & -0.59 & 0.57 \\
\hline $\begin{array}{l}\text { Number of Tenants in the } \\
\text { Property }\end{array}$ & 0.01 & 0.23 & 0.05 & 0.96 \\
\hline Vacancy Percentage & 0.27 & 0.60 & 0.45 & 0.66 \\
\hline $\begin{array}{l}\text { Number of Units in the } \\
\text { Property }\end{array}$ & 385.44 & 114.36 & 3.37 & 0.00 \\
\hline $\begin{array}{l}\text { Granularity of the Property } \\
\text { Income Relating to Individual } \\
\text { Property Tenancies }\end{array}$ & -0.12 & 0.13 & -0.91 & 0.37 \\
\hline $\begin{array}{l}\text { Percentage of Deprivation in } \\
\text { the Local Area of the Property }\end{array}$ & 0.27 & 0.12 & 2.30 & 0.04 \\
\hline $\begin{array}{l}\text { Distance to Motorway in } \\
\text { KMS }\end{array}$ & 0.68 & 2.46 & 0.28 & 0.79 \\
\hline Distance to A-road KMS & -1.23 & 0.58 & -2.11 & 0.05 \\
\hline $\begin{array}{l}\text { Distance to Major Town in } \\
\text { kms (Central Post Office) }\end{array}$ & -0.0013 & 0.0005 & -2.37 & 0.03 \\
\hline Gross Internal Area (sqm) & -0.27 & 0.82 & -0.33 & 0.75 \\
\hline $\begin{array}{l}\text { Weighted Average Lease } \\
\text { Expiry at Oct 2017 in Years }\end{array}$ & 0.55 & 0.37 & 1.52 & 0.15 \\
\hline $\begin{array}{l}\text { Property Performance per } \\
\text { annum }\end{array}$ & & & & \\
\hline
\end{tabular}

Table 4 provides results of the linear regression analysis, and showed that MLI property values (as the dependent variable) has a very strong direct relationship with i) granularity of property income, and to a lighter extent ii) distance from nearest Motorway. This compared to a strong inverse relationship with iii) distance to major town centre and iv) MLI gross internal floor area (extremely low coefficient reading). The P-values of the explanatory (independent) factors showed that there is a low probability and that these results occurred randomly.

The panel data sets were separately examined for multicollinearity using the variance inflation factor (VIF) test. The four explanatory variables had VIF readings of i) granularity of property income: 2.35 , ii) distance from nearest Motorway: 1.22 , iii) distance to major town 
centre: 1.33 and iv) MLI gross internal floor area: 3.77. As these values were between 1 and 5 it indicates moderate correlation between the given exploratory variable and other explanatory variables in the model. According to Statology (2020) this range is often not severe enough to require further attention for multicollinearity in regression analysis.

Also as part of the study, the data was converted to natural logs (including: semi-log, log-log) to examine if non-linear data provided a better regression reading to the above linear regression analysis. In acknowledging the theoretical benefits of selecting the log function for a hedonic regression (improved error terms etc), the best non-linear regression readings were lower than the linear regression reading and with the simular explanatory variables, the linear data regression analysis was preferred as the explanatory variable coefficients can be easily interpreted. The single-equation linear hedonic model design fits the purpose of the study.

According to Table 3, the model highlights the value-affecting characteristics of the selected MLI estates determinants are as follows:

\section{Property Income Granularity}

The strong positive relationship between Property Value and Income Granularity shows that the greater the income diversification, the higher the property value. This result dictates that if a MLI estate has different occupiers in each unit, its Market Value should be relatively higher than an equivalent single tenanted property. In addition, the income spread benefits from MLI reliance on the typical SME tenant being small owner-managed businesses.

\section{Distance to Town Centre and from Motorway}

As there is a strong converse relationship between Market Value and Distance to Major Town (central post office), the research demonstrates the importance of urban location for MLI estates to densely populated towns and cities with the average distance to the studied MLI portfolio of $4.5 \mathrm{kms}$. Gerald Eve (2018) support this with data showing that units occupied by local businesses generally generate the strongest returns.

The motorway independent variable highlighted a positive relationship to MLI property values, which makes sense as motorway routes are on the perimeter of most dense urban locations. The average MLI property distance to the nearest motorway was $13 \mathrm{kms}$ which demonstrates the emphasis of MLI occupies to predominantly service the local community. In comparing location of MLI estates, the MLI size and occupier types can influence distance to major A-road/motorway. Those that offer logistics and warehouse facilities (the last mile) would likely require ease of access to major road infrastructure. On a larger data set this could be modelled and reviewed.

\section{Gross Internal Floor Area}

The extremely low converse relationship reading between Market Value and Gross Internal Area indicates that the bigger the gross internal area of the property, the lower the market value. In part this outcome can be explained by the economy of scale theory and by taking a closer look at the occupiers of multi-let industrial estates. The bigger the space, the lower the achievable rate per sqm. Also, businesses occupying such units are small and medium in size and can still be growing. They are interested in affordable space then can move into now rather than a bigger space that they will be able to utilise in the future (Stenprop, 2019a).

In summary, the key four data generating independent variable: granularity of property income, distance from nearest motorway, distance to major town centre, and MLI gross internal floor area can infer the causal relationships between the independent and dependent 
variables and would be valuable for prediction and forecasting modelling with supported statistical tests.

\section{Market Value Model}

The hedonic pricing approach can explain relationships between variables and help to build a predictive model. In this instance, the regression equation can model property prices to the given MLI estate valuations. Table 5 details the differences between the multi-let properties' values - the original and the modelled.

\section{Table 5 Difference between Original and Modelled MLI Real Estate Values}

\begin{tabular}{|l|c|}
\hline \multicolumn{2}{|c|}{ Valuation data } \\
\hline Number of data points & 26 \\
\hline Mean & $3.4 \%$ \\
\hline SD & $18.9 \%$ \\
\hline SD +2 & $41.1 \%$ \\
\hline SD-2 & $-34.4 \%$ \\
\hline Median & $2.4 \%$ \\
\hline Kurtosis & 0.35 \\
\hline Skewness & 0.59 \\
\hline Range & $78.2 \%$ \\
\hline Min & $-28.9 \%$ \\
\hline Max & $49.3 \%$ \\
\hline
\end{tabular}

Table 5 shows a summary of the descriptive statistics of the differences between the original value and the modelled price of the selected properties. The low mean reading $(3.4 \%)$ confirms that the majority of the modelled values are close to the original market values. Although the very high reading of the standard deviation (18.9\%) is a concern, it can be explained by the outliers, specifically one property has a modelled value nearly $50 \%$ higher than the original value published in the dataset. There is no obvious reason for this, except a relatively low passing rental when compared to the MLI portfolio. The low kurtosis $(0.35)$ shows that data points are generally close to the mean. The low skewness also signifies that the distribution of data is normal.

These results signify that the hedonic regression model (if used in accordance with its limitations) can give a market valuation of the MLI estates alongside traditional valuation methods. The final step is to examine the relationship between the original and modelled MLI real estate values. This can be achieved by the chi square goodness of fit test. The data yields a value for the chi squared statistic of 62.52 and this exceeds 36.41 from the chi squared distribution table at the 0.05 level of significance. Since $62.52>36.41$ the null hypothesis can be rejected, and so demonstrate no significant statistical differences between the modelled and the observed values.

\section{CONCLUSION}

MLI estates are an emerging investment grade asset class which offers exposure primarily to the dynamic SME occupier sector. Significantly the SME marketplace has continuously grown over the past 20 years and is supported by government policies, current economic 
conditions and new technologies which in part, offer important advances in digital connectivity along the supply chain.

In highlighting MLI property opportunities, current research reports predominantly look at market coverage. Looking behind the figures, this exploratory research utilising a hedonic price model, shows key value drivers of MLI properties are i) Granularity of the property income, ii) Distance from the nearest motorway, iii) Distance to the nearest town centre and iv) Gross internal floor area. A chi-square goodness of fit test supports the hedonic pricing module to actual MLI property values across the portfolio with a mean variance of $3.2 \%$ and an acceptable low $P$ reading.

There are several key features evident in this research. Foremost, MPI properties have a range of physical, financial and locational characteristics unique to the sector which separate the asset class from alternative industrial property categories: Logistics, Solus Warehouses and Trade Counters properties. In offering flexible space, arranged in terraces and let primarily to local SME tenants, property asset managers need to look beyond the physical real estate to develop services to support the occupiers. For real estate investors there are opportunities to enhance income through efficiencies of scale, new technology platform, and innovative management techniques. This creates the ability to offer a range of add-on services and products to the space occupier/customer.

Knowledge provided in this research paper can support an active MLI property strategy that can offer the property investor superior long-term returns. In providing a platform for future research, occupier types and range of floor areas can lead to a more in-depth understanding of this emerging real estate asset class. The challenge is to capture these opportunities in a fragmented real estate market that services one of the major business sectors in the UK economy.

\section{REFERENCES}

Alonso, W. (1964). Location and Land Use: Toward a General Theory of Land Rent, Harvard University Press, Cambridge, MA.

Ahlfeldt, G. (2011) If Alonso was right: Modelling accessibility and explaining the residential land gradient. Journal of Regional Science, Vol. 51, pp. 318-338.

Bourassa, S., Hamelink, F., Hoesli, M., MacGregor, B. (1999) Defining housing submarkets, Journal of Housing Economics, Vol. 8, pp. 160-183.

Brynjolfsson, E. and McAfee, A. (2014). The Second Machine Age: Work, Progress and Prosperity in a Time of Brilliant Technologies, W.W. Norton, New York.

Cushman and Wakefield. (2017). Well Work Place: Making Spaces Human Again, Cushman and Wakefield, London.

European Commission. (2018). SBA Fact Sheet: United Kingdom, European Commission, Brussels.

Gerald Eve. (2018). Multi-Let - The Definitive Guide to the UK's Multi-let Industrial Property Market, Gerald Eve, London.

Goldin, I. and Kutarna, C. (2017). Age of Discovery: Navigating the Storms of our Second Renaissance, Bloomsbury, London.

IPF.(2018). The Size and Structure of the UK Property Market - End-2017 Update Data and Charts, Investment Property Forum, London. 
Lancaster, K. (1966). A New Approach to Consumer Theory, Journal of Political Economy, Vol.74, pp. 132-157.

LEP Network. (2018). Developing Effective Local Industrial Strategies, Local Enterprise Partnership, Corby, Northamptonshire.

Malpezzi, S. (2003). Hedonic Pricing Models: A Selective and Applied Review, in Housing Economics and Public Policy, T Sullivan and K Gibbs (Eds.) Blackwell, Oxford.

McMillen, D.P. and Redfearn, C.L. (2010) Estimation, Interpretation, and Hypothesis Testing for Nonparametric Hedonic House Price Functions. Journal of Regional Science, Vol. 50, pp. $712-733$.

MSCI. (2018). Industrial in the Limelight: Secular Shift or Cyclical Rotation? MSCI, New York.

OECD (2018). Promoting Innovation in Established SMEs: Parallel Session 4, OECD SME Ministerial Conference, Mexico City, 22-23 February.

Property Industry Alliance. (2017). Property Data Report 2017: Facts and Figures About the UK Commercial Property Industry to year-end 2016, Property Industry Alliance, London.

Rhodes, C. (2018). Business Statistics: Briefing Papers No. 06152, House of Commons Library, Westminster, London.

Statology. (2020). How to Calculate VIF in Excel, Statology, Available from: https://www.statology.org/how-to-calculate-vif-in-excel/ (Accessed 28 April 2020).

Schroder. (2014). Multi-let Industrial Estates: More Than Just Your Average Manufacturer, Schroder Property Investment Management Limited, London.

Spence, M. (2011). Equity and Growth in a Globalizing World, World Bank Publications, New York.

Sirmans, G., Macpherson, D. and Zietz, E. (2005). The Composition of Hedonic Pricing Models, Journal of Real Estate Literature, Vol 13, pp. 3-43.

Stenprop. (2019a). MLI Space, Stenprop Viewed 30 July 2019, https://stenprop.com/ourbusiness/mli-space/

Stenprop. (2019b). Stenprop Annual Report 2019, Stenprop, London

Wei, C.H. and Qi, F. (2012) On the estimation and testing of mixed geographically weighted regression models, Economic Modelling, Vol. 29, pp. 2615-2620.

Xiao, Y. (2017). Urban Morphology and Housing Market, Tongii University Press and Springer Nature Singapore Pte Ltd, DOI: 10.1007/978-981-10-2762-8 2. 